\title{
Conference report: Second conference of the Middle East and North Africa newborn screening initiative: Partnerships for sustainable newborn screening infrastructure and research opportunities
}

\author{
Danuta Krotoski, PhD ${ }^{l}$, Sorrel Namaste, $M H S^{l}$, Randa Kamal Raouf, MD', Ibrahim El Nekhely, MD', \\ Michele Hindi-Alexander, $P h D^{I}$, Gilian Engelson, MPH ${ }^{I}$, James W. Hanson, $\mathrm{MD}^{I}$, \\ and R. Rodney Howell, $M D^{1}$; on behalf of the MENA NBS Steering Committee
}

\begin{abstract}
The second conference of the Middle East and North Africa newborn screening initiative: partnerships for sustainable newborn screening infrastructure and research opportunities was held in Cairo, Arab Republic of Egypt on April 12 to 14, 2008. Policy makers, health ministry representatives, health care providers, and experts from the region, Europe, Asia, and North America participated. The primary outcome was development of country plans of action to implement or expand newborn screening programs. Country representatives were grouped by current levels of national newborn screening activities based on a Needs Assessment Survey for national newborn screening programs and assisted by international technical experts. The Needs Assessment Survey provided information on the level of newborn screening in each country, strengths and barriers to implementation of newborn screening programs, and identified areas for research. Newborn screening programs require an integrated system of laboratories, health care providers, and educators, thus, the infrastructure put in place to screen for one condition should support expansion to other conditions. Congenital hypothyroidism was selected for initiating newborn screening programs because of its high prevalence, availability of screening methods, and cost-effective intervention. To this end, the conference provided technical sessions on screening and treatment of congenital hypothyroidism, performance standards, quality assurance, follow-up interventions, and patient management. In addition, presentations highlighted the value of integrating research into newborn screening programs as they are established and in evaluating outcomes. Research opportunities were identified at a postconference workshop sponsored by the US Civilian Research Development Foundation. Genet Med 2009:11(9):663-668.
\end{abstract}

Key Words: newborn screening, Middle East and North Africa, genetic disorders

Ther here has been increased interest in developing and strengthening newborn screening (NBS) programs throughout the world. ${ }^{1-4}$ Advances in genetics and technology have led to the

From the ${ }^{1}$ Eunice Kennedy Shriver National Institute of Child Health and Human Development, US National Institutes of Health, DHHS, Rockville, Maryland; and ${ }^{2}$ Children with Special Needs Program, Ministry of Health and Population, Arab Republic of Egypt.

Danuta Krotoski, NICHD, 6100 Executive Boulevard 4A05B, Bethesda, MD 20892-7510. E-mail: krotoskd@mail.nih.gov.

Disclosure: The authors declare no conflict of interest

Supplemental digital content is available for this article. Direct URL citations appear in the printed text and are provided in the HTML and PDF versions of this article on the journal's Web site (www.geneticsinmedicine.org).

Submitted for publication December 11, 2008.

Accepted for publication April 13, 2009

Published online ahead of print July 14, 2009

DOI: $10.1097 /$ GIM.0b013e3181ab2277 development of more effective detection and treatment of congenital and genetic disorders. The availability of interventions that can ameliorate the effects of a number of genetic conditions has led countries to develop strategies to identify and prioritize conditions to be screened. ${ }^{5-7}$

Establishing or expanding NBS in the Middle East and North Africa (MENA) is particularly timely because many countries in the region are undergoing an epidemiologic transition that has resulted in a dramatic decline in child and infant mortality (Table 1) increasing the public health importance of genetic conditions and other congenital disorders. ${ }^{89}$ In addition, cultural factors have lead to a larger number of consanguineous marriages with a consequent corresponding increased expression of recessive and potentially deleterious conditions in newborns. ${ }^{10-13}$ Furthermore, there is a growing recognition in the region of the value of NBS and its role in preventing or ameliorating mental retardation, physical disability, neurologic damage, and even death in conditions amenable to screening particularly in those conditions in which treatment is simple and relatively inexpensive. ${ }^{14}$

After the 2006 visit of a delegation from the National Institutes of Health to North Africa led by Dr. Elias Zerhouni, the Ministry of Health (MOH) of the Kingdom of Morocco, the Eunice Kennedy Shriver National Institute of Child Health and Human Development of the US Department of Health and Human Services, together with 20 partners organized the conference, strengthening newborn screening in the Middle East and North Africa, to assess the status of NBS in the region. ${ }^{15}$ The conference, held in Marrakech, Morocco, was attended by members of ministries of health academic institutions, private sector, and parent/advocacy representatives from 18 countries in the region and 11 countries in Europe, Asia, and North America. The primary outcome was publication of the Marrakech Declaration (Appendix, Supplemental Digital Content 1, http://links.lww.com/GIM/A81), which affirmed NBS as a universal public health priority for the region and recommended that each country screen for at least one condition. A regional steering committee was established to implement the declaration's recommendations and to plan for the next regional meeting (Appendix, Supplemental Digital Content 2, http://links.lww.com/GIM/A82). Membership on the committee consisted of representatives from multilateral organizations, ministries of health, universities, and other health care providers from the region as well as international collaborators from the United States, Europe, and Asia/Pacific.

NBS requires an integrated system of laboratories, health care providers, and educators. Thus, the infrastructure put in place to screen for one condition should support expansion to other conditions. For those countries that have not yet initiated a national NBS program, the steering committee identified 
Table 1 MENA NBS conference report

\begin{tabular}{|c|c|c|c|c|c|c|c|}
\hline \multirow[b]{2}{*}{ Country } & \multirow[b]{2}{*}{ Population } & \multirow[b]{2}{*}{ No. of births } & \multirow[b]{2}{*}{$\begin{array}{l}\text { Infant mortality } \\
\text { rate (per } 1000 \text { live births) }\end{array}$} & \multirow[b]{2}{*}{$\begin{array}{l}\text { No. infants } \\
\text { screened }^{a}\end{array}$} & \multirow[b]{2}{*}{$\begin{array}{c}\text { Home } \\
\text { delivery }(\%)^{b}\end{array}$} & \multicolumn{2}{|c|}{ Consanguinity $(\%)^{b}$} \\
\hline & & & & & & $\begin{array}{l}\text { First } \\
\text { cousin }\end{array}$ & $\begin{array}{l}\text { Second } \\
\text { cousin }\end{array}$ \\
\hline Algeria & $33,000,000$ & 500,000 & 33 & - & 9 & 22 & 11.3 \\
\hline Bahrain & $1,000,000$ & 15,000 & 9 & - & 2 & 12 & 8 \\
\hline Egypt & $76,000,000$ & $1,800,000$ & 29 & $1,700,000$ & 34.4 & 18.2 & 7.3 \\
\hline Iran & $70,000,000$ & $1,130,000$ & 30 & $1,000,000$ & - & 30 & 3 \\
\hline Jordan & $6,500,000$ & 150,200 & 19 & - & 1 & 32 & 26 \\
\hline Kuwait & $2,800,000$ & 50,000 & 9 & - & $<1$ & 33.5 & 0.8 \\
\hline Lebanon & $4,000,000$ & 70,000 & 26 & 22,000 & $<1$ & - & - \\
\hline Libya & $5,419,000$ & 126,223 & 17 & - & $<1$ & 30 & - \\
\hline Morocco & $30,653,000$ & 647,229 & 34 & - & 38.8 & 12.3 & - \\
\hline Oman & $1,883,576$ & 44,116 & 10 & 43,645 & 2 & 38.6 & 13 \\
\hline Pakistan & $164,741,924$ & $4,358,000$ & 78 & - & 80 & - & - \\
\hline Palestinian Authority & $3,761,646$ & 129,400 & 20 & - & 9.9 & 27.5 & 17.8 \\
\hline Qatar & $1,000,000$ & 15,262 & 18 & 15,262 & $<1$ & $>54$ & - \\
\hline Saudi Arabia & $24,573,000$ & 671,000 & 18.6 & 92,280 & - & 28.4 & 14.6 \\
\hline Syria & $19,043,000$ & 532,000 & 12 & - & - & - & - \\
\hline Tunisia & $10,000,000$ & 150,000 & 19 & - & - & 23 & 12 \\
\hline UAE & $4,000,000$ & 70,000 & 8 & 70,000 & 0 & 30 & 20 \\
\hline Yemen & $19,721,643$ & 839,000 & 75 & - & 50 & 17.5 & 37 \\
\hline
\end{tabular}

Demographic characteristics of participating countries demonstrate a heterogeneity in population size infant mortality, home births, and levels of consanguinity in the region that lead to different changes in establishing newborn screening programs. These data were provided by participants in response to the MENA NBS Country Situation Analysis Survey. Data on the annual number of infants screened are provided for countries that reported national NBS programs; the number of infants screened as part of pilot studies was not included.

${ }^{a}$ Refers to children screened under National NBS programs.

${ }^{b}$ Numbers provided by MENA Situation Survey respondents.

congenital hypothyroidism $(\mathrm{CH})$, which is on the US NBS panel, ${ }^{5}$ as a priority model because of its high prevalence, availability of screening methods, and cost-effective intervention. ${ }^{16}$ A Congenital Hypothyroidism Training Working Group was formed to develop educational materials for policy makers and training modules for health care professionals, researchers, and affected families.

The steering committee recognized that accurate needs assessment and better information regarding current status of NBS in the region is a high priority to support countries and policy makers in the development of NBS programs. A Survey Working Group was established that developed a Country Situation Analysis Survey for which country representatives were asked to provide nationally representative data.

\section{CONFERENCE DESCRIPTION}

The second conference of the Middle East and North Africa newborn screening initiative: partnerships for sustainable newborn screening infrastructure and research opportunities was held in Cairo, Egypt on April 11 to 13, 2008 and was attended by over 30 policy makers, health care providers, health ministry representatives, experts and family, and advocacy representatives from 17 countries in the region, Europe, Asia, and North
America. The conference was organized by the MENA NBS steering committee, which ensured that the meeting agenda addressed issues embedded in the needs of the region (Table 1).

The conference was composed of two parts: the first provided guidance for building national NBS systems and development of national plans of action, and the second provided technical information and practical applications. Presentations during the first half included an overview of NBS systems including infrastructure, education, and legislation, as well as ethical, legal, and cultural considerations. They also addressed the importance of integrating research into NBS programs and how development of successful research collaborations can strengthen identification and treatment of detected conditions as well as effectiveness of program outcomes. The results of the Country Situation Analysis Survey on national NBS programs were presented and served as a basis for the working groups for developing country plans of action. After plans were developed, technical experts provided training on screening for the treatment of $\mathrm{CH}$ as well as on performance standards and quality assurance. Because development of partnerships can enhance implementation of NBS and follow-up interventions, a panel on building partnerships and collaborations provided examples of in country and multinational partnerships. The conference ad- 
dressed the issue of integrating research into NBS from bench to bedside presenting translational models and new technologies.

Research opportunities were further discussed at a postconference workshop sponsored by the Civilian Research Development Foundation, at which a competition for proposal planning grants for regional networks for NBS-related research was announced.

\section{Needs assessment}

The Country Situation Analysis Survey was sent to participants requesting that national information be obtained from the appropriate national authorities. The responses that were received provided national data but in some cases only regional information was provided. Because accurate national information serves as a baseline on which to plan NBS activities and on which to measure the impact of NBS programs, meeting participants strongly recommended that national information be obtained and verified from all countries to have an accurate baseline. With that caveat, the results revealed significant demographic heterogeneity in the region and diverse experiences with NBS (Verbal Communication, Cairo, Egypt). The MENA countries in attendance have a population of over 500 million people with approximately 12 million births per annum (Table 1). Infant mortality rates range between 9 and 29 per thousand with the exception of Yemen and Pakistan where the rates are more than 75 per thousand births. ${ }^{8}$ Home deliveries were estimated to be $34 \%$ in Egypt, $38 \%$ in Morocco and $81 \%$ in Pakistan whereas they are $<1 \%$ in the Gulf countries. Consanguineous marriages between first and second cousins were reported to be $12 \%$ in Morocco and Bahrain to over $23 \%$ in the other countries. The highest rate was reported from Qatar, where over $54 \%$ of marriages are between first cousins.

Data from the survey also provided information regarding the status of national NBS programs (Women delivering in private clinics have access to NBS services though data has not been systematically collected on this population and as a consequence was not included in the survey). National NBS programs have been established in Egypt, the Palestinian Authority, Iran, Bahrain, Oman, Qatar, Saudi Arabia, and the United Arab Emirates (Table 1). In Lebanon, private hospitals have undertaken screening programs that now cover much of the country, though they anticipate working with the Ministries of Health and Education to establish a national NBS Program (Appendix, Supplemental Digital Content 3, http://links.lww.com/GIM/A83). Morocco, Tunisia, Pakistan, Jordan, Kuwait, and Syria have established or are planning pilot programs, whereas Libya, Algeria, and Yemen reported not having programs at the time of the meeting. All of the countries plan on screening for $\mathrm{CH}$ and phenylketonuria (PKU). To date only three countries, Lebanon, Saudi Arabia, and Qatar, are using tandem mass spectrometry and screen for over 20 conditions (Table 2). Of the countries without national programs, Libya, Pakistan, and Syria reported not having existing plans for NBS.

The survey also provided information on specific strengths of particular programs and barriers to implementation of national NBS programs. These included the need for political support, increased financial and human resources, and greater coordination within the region and with the international community. Of great importance was the need for improved technical resources for diagnostic confirmation, follow-up, and patient management. To this end, regional collaboration could leverage both human and financial resources. Additionally, the survey identified areas in which research is needed. These include epidemiologic studies that will provide data on prevalence, genomic characterization, and identification of risk factors. Economic research on cost-benefit analyses was seen as critical for informing the political authorities.

\section{National plans}

The primary goal of the conference was to develop national plans of action for NBS based on the situation in each participating country. Country representatives were asked to identify the current status of NBS and next steps. On the basis of their responses, representatives were assigned to one of three working groups: (1) those that had not yet started NBS programs, (2) those that had performed pilot programs and (3) those that had a national or regional program. The groups were charged to (1) identify solutions to practical problems faced in the establishment of NBS programs and associated research infrastructure and (2) develop individual national draft plans of action for development or expansion of NBS in their country.

Countries in Groups 1 and 2 focused their efforts on structuring a program for $\mathrm{CH}$ screening. For those countries in Group 3 that already reported national programs, plans were focused on strategies to strengthen and enhance the current activities. Country plans benefited from the experience of other countries and advice from regional and international experts. Finalized plans contained specific information on country goals, leadership, steps for implementation, and follow-up were presented at the meeting and were to be communicated to the policy makers.

There was a significant diversity within each of the groups in relation to population size, per capital income, health systems, insurance coverage, and differences in the stages of epidemiological transition. In those countries that have established NBS, there has been strong political support. This was identified as an important barrier to implementation of programs by countries in the process of establishing NBS systems and also by those wishing to expand national NBS systems either by adding new conditions or by increasing population coverage. All plans developed at the conference identified leadership for NBS activities, primarily in the $\mathrm{MOH}$, and, in many cases, identified the composition and membership of advisory committees. They also provided target dates and identified conditions for expansion of NBS. All plans also have in place guidelines for collection and testing of specimen and identify steps for follow-up. A summary of the National Plans of Action can be found in Appendix, Supplemental Digital Content 3, http://links.lww.com/GIM/A83 (Country plans for Algeria and Iran are not available as representatives were not able to be present at the conference).

\section{Group 1: Libya, Morocco, Syria, Yemen}

Countries in Group 1 have not begun national NBS. Implementation of a pilot NBS program was their primary goal. Each country brought a different experience to the discussion. Morocco had developed a detailed plan of action/protocols after the 2008 Marrakech conference; Syria had developed plans for a pilot $\mathrm{CH}$ screen in cooperation with the International Atomic Energy Agency; whereas Libya and Yemen had not yet begun developing a plan of action at the time of the meeting. All four countries planned on initiating screening with $\mathrm{CH}$ and may include PKU and/or hearing assessment to some of the screening panels (Appendix, Supplemental Digital Content 3, http://links.lww.com/GIM/A83). They identified common barriers to implementation such as the need for trained professionals and obtaining financial and political support. An important commonality was the emphasis placed on having the $\mathrm{MOH}$, medical professionals, and advisory groups work closely together to meet their goals and objectives. Plans were tailored to individual countries and covered topics such as laboratory and 
Table 2 Conditions screened for in the MENA region based on data provided in the MENA NBS Country Analysis Survey

\begin{tabular}{|c|c|c|}
\hline Status & Country & Conditions screened by National or Pilot NBS programs \\
\hline \multirow[t]{2}{*}{ National MS/MS NBS programs } & Qatar & $\begin{array}{l}\text { CH, CAH, PKU, HPA, BS, ASA, MSUD, HCY, CIT, TYR I1, } \\
\text { GALT, BIOT, MMA, PROP, GA I, IVA, 3MCC, MAD, IBDH, } \\
\text { MCAD, VLAD, LCHAD, SCAD, CTD, CPT, I,-II, HMG, } \beta \mathrm{KT}\end{array}$ \\
\hline & Saudi Arabia & $\begin{array}{l}\text { CH, MCAD, PKU, CAH, MSUD, ASA, CIT, HMG, IVA, PROP, } \\
\text { ßKT, GA I, MMA, 3MCC, BIOT, GALT identified by MS/MS }\end{array}$ \\
\hline Private MS/MS & Lebanon & $\begin{array}{l}\text { CH, PKU, G6PD, GALT, MSUD, OTC, IVA, MCAD, HMG, TYR, } \\
\text { HMG, PROP, BIOT, MMA, HCY, 3MCC, CUD, IVA, CACT, } \\
\text { VLCAD, SS-Hb, GSSD, GS }\end{array}$ \\
\hline \multirow[t]{6}{*}{ National NBS programs } & Oman & $\mathrm{CH}, \mathrm{SS}-\mathrm{Hb}, \mathrm{BIOT}$ and G6PD \\
\hline & UAE & $\mathrm{CH}, \mathrm{PKU}, \mathrm{CAH}, \mathrm{SS}-\mathrm{Hb}$ hearing \\
\hline & Palestine & $\mathrm{CH}, \mathrm{PKU}$ \\
\hline & Bahrain & G6PD, HB-SS, $\alpha$ - and $\beta$ thallassemias \\
\hline & Egypt & $\mathrm{CH}$ \\
\hline & Iran & $\mathrm{CH}$ \\
\hline \multirow[t]{4}{*}{ Pilot NBS programs } & Jordan & $\mathrm{CH}$ and $\mathrm{PKU}$ \\
\hline & Kuwait & $\mathrm{CH}$ and $\mathrm{PKU}$ \\
\hline & Tunisia & $\mathrm{CH}, \mathrm{PKU}$ \\
\hline & Pakistan & $\mathrm{CH}$ \\
\hline \multirow[t]{2}{*}{ Pilot NBS programs planned } & Syria & $\mathrm{CH}$ \\
\hline & Morocco & $\mathrm{CH}$, hearing screening \\
\hline \multirow[t]{3}{*}{ Developing plans for pilot programs } & Algeria & $\mathrm{CH}, \mathrm{PKU}$ \\
\hline & Libya & $\mathrm{CH}, \mathrm{PKU}$ \\
\hline & Yemen & $\mathrm{CH}, \mathrm{PKU}$ \\
\hline
\end{tabular}

ASA, Argininosuccinic academia; BIOT, biotinidase deficiency; $\beta \mathrm{KT}, \beta$-ketothiolase deficiency; BS, Defects of biopterin cofactor biosynthesis; CACT, carnitine: acylcaranitine translocase deficiency; CAH, congenital adrenal hyperplasia; CF, cystic fibrosis; CH, congenital hypothyroidism; CIT, citrullinemia; CPT I-II, carnitine palmitoyltransferase I and II deficiency; CUD, primary carnitine deficiency; G6PD, glucose 6-phosphate dehydrogenase deficiency; GA I, glutaric academia I; GALT, galactosemia; GSSD, glutathione sythetase deficiency; HBSS, sickle cell anemia; HB $\alpha$ Th, $\alpha$ Thalassemia; HB $\beta$ Th, $\beta$ Thalassemia; HMG-C0A, 3-hydroxy-3methylglutaryl-coenzyme A (CoA) lyase deficiency; HCY, homocystinuria; HEAR, hearing loss; HMG, 3-hydroxy 3-methyl glutaric aciduria; HPA, benign hyperphenylalaninemia; IBDH, isobutyryl-CoA dehydrogenase deficiency; IVA, isovaleric academia; LCHAD, long-chain L-3-OH acyl-CoA dehydrogenase deficiency; MAD, multiple acyl-CoA dehydrogenase deficiency; MCAD, medium-chain acyl-CoA dehydrogenase deficiency; 3MCC, 3-methylcrotony-CoA carboxylase deficiency; MMA, methylmalonic academia; MSUD, maple Syrup (urine) Disease; OTC, ornithine transcarbamylase deficiency; PKU, phenylketonuria; PROP, propionic academia; SCAD, short chain acyl-CoA dehydrogenase deficiency; TYR I, tyrosinemia type I; VLCAD, very long-chain acyl-CoA dehydrogenase deficiency.

follow-up procedures. Broad timelines were developed and all countries planned to begin their pilot program within a year from the conference date. A joint recommendation was the establishment of a MENA regional laboratory that could lead to greater cost effectiveness and efficiency for countries with small populations.

\section{Group 2: Jordan, Kuwait, Lebanon, Pakistan, Tunisia}

Group 2 countries have completed pilot studies for at least one condition and anticipated expansion to national programs. The Marrakech Declaration had served as a catalyst for further activities in NBS in a number of the countries in this group. In Lebanon, over a quarter of the country's newborns are screened for over 20 conditions through university-based NBS programs. In Kuwait, approximately $5 \%$ of newborns are screened for $\mathrm{CH}$ and PKU through private testing with plans to expand to a national program. Jordan has completed a pilot program on $\mathrm{CH}$ in two governorates and has trained health professionals in all of the country's governorates in preparation for the launch of a national program. Tunisia completed pilot studies on $\mathrm{CH}$ in cooperation with the International Atomic Energy Agency and on congenital adrenal hyperplasia and PKU and is planning to develop a national plan. Pakistan has put in place a pilot program for $\mathrm{CH}$ at Aga Khan University. The plans of action for these countries are presented in Appendix, Supplemental Digital Content 3, http://links.lww.com/GIM/A83.

\section{Group 3: Bahrain, Egypt, the Palestinian Authority, Oman, Qatar, Saudi Arabia, United Arab Emirates}

All countries in Group 3 screen for at least one condition, primarily $\mathrm{CH}$, and most screen for two or more conditions. Both Qatar and Saudi Arabia use tandem mass spectrometry for a large panel of metabolic conditions (Table 2). Regarding expansion of NBS programs, the participants agreed that, where resources are an issue, increased coverage was more important than number of conditions added and that current programs should be evaluated before large expansions are considered. In 
some countries, population-based pilot studies are planned to assess need and to aid with prioritization of new conditions. A strategy to facilitate development of NBS programs used by some of the countries in this group has been to enter into partnerships both within and outside the region. For example, Qatar has partnered with the University of Heidelberg in Germany to establish tandem mass spectrometry (MS/MS) screening for metabolic conditions. Bahrain and the French Institut National de la Santé et de la Recherche Médicale are developing an integrated system of NBS for hemoglobinopathies. The Egyptian $\mathrm{MOH}$ and the US Agency for International Development cooperated in piloting a national NBS program for $\mathrm{CH}$. Universal NBS was established in The Palestinian Authority in collaboration with Israel. All countries have plans for linking screening results to treatment and long-term follow-up, and to this end recommended addressing the issue for formulas and other nutritional supplements. Action plans for this group are summarized in Appendix, Supplemental Digital Content 3, http://links.lww.com/GIM/A83.

In addition to the barriers expressed by the other two groups, Group 3 also added the issue of geographic challenges to the list. In some countries, large distances and isolation may limit accessibility for screening the entire population and transportation of materials and reagents, such as quality assurance kits. They also voiced the need for policies that mandate NBS. Finally, there was a clear need identified to develop databases and communication systems that would link children identified through screening with providers for management of long-term treatment and follow-up.

\section{RECOMMENDATIONS FOR FURTHER ACTION}

Participants reiterated the need for regular regional meetings on NBS and recommended that the next conference address resources that would support NBS activities across countries. These include forming a working group to address data collection and systems that will follow identified children from the initial diagnosis through treatment and strategies for second-tier testing. They recommended examining strategies for establishing regional second-tier testing resources. They also strongly supported development of population studies that could provide incidence of conditions, risk factors, and facilitate cost-benefit analyses.

The following items were recommended to the steering committee for further action:

- Present country plans to the appropriate country authorities for implementation.

- Request that countries verify and revise their responses to the Country Situation Analysis Survey to contain accurate national figures for NBS that can serve as a baseline for assessing progress.

- Hold annual regional meetings and more frequent local networking meetings to support capacity in NBS.

- Develop a research training module for $\mathrm{CH}$ that would strengthen research and program infrastructure for data collection and quality assurance important for measuring the program effectiveness.

- Establish partnerships to leverage technical, financial, and human capacity.

\section{POSTMEETING WORKSHOP}

Integrating research into national newborn screening programs: MENA newborn screening research agenda workshop co-organized by the US Civilian Research and Development (CRDF) Foundation, was held after the conference to discuss research opportunities and the availability of small funds to establish regional NBS research networks though the CRDF planning grants.

\section{Next steps}

Building on the activities and recommendations presented in this report, we are in the process of planning the next conference that will address progress in implementing country plans will be assessed and activities developed. The steering committee has also established working groups to address laboratory quality assurance and specimen collection and to develop common definitions and indicators.

\section{ACKNOWLEDGMENTS}

Conference supported with funds from the NIH, CDC, HRSA, INSERM, ISNS, ACMG, CRDF, Perkin Elmer, Genzyme, HVD Life Sciences, Luminex, Milupa Metabolics.

The Organizers express their special appreciation to sponsors of the meeting: U.S. Department of Health and Human Services: National Institutes of Health, Eunice Kennedy Shriver National Institute of Child Health and Human Development, Office of Rare Diseases, Fogarty International Center, National Institute of Deafness and other Communication Disorders, Centers for Disease Control and Prevention, Health Resources and Services Administration, Institut National de la Santé et de la Recherche Médicale; American College of Medical Genetics; National Newborn Screening and Genetics Resource Center; US Civilian Research \& Development Foundation; International Society for Neonatal Screening; PerkinElmer, Genzyme, HVD Life Sciences, Luminex, Zentech, Milupa Metabolics.

In addition, we extend our special thanks to the Ministry of Health and Population of the Arab Republic of Egypt and are especially grateful to the Assistant Minister of Health and Population, Dr. Nasr El Sayed, for his warm welcome and continued support of this activity. We are indebted to Mrs. Divna Cigovska Étienne and her colleagues at PAR3 for providing the logistical support for the conference and to NICHD staff Sondra Sheriff, Christel Richardson, and Mr. Paul Errett. We also thank Ms. Christine Salaita for help with finalization of this document.

The members of the steering committee are as follows: Sana Al Hait, Jordan; Zuhair Al-Hassnan, Saudi Arabia; Ali Bensalah, Morocco; Habiba Chaabouni, Tunisia; Jean-Louis Dhondt, France; Ibrahim El Nekhely, Egypt; Harry Hannon, USA; James Hanson, USA; R. Rodney Howell, USA; Randa Kamal Raouf, Egypt; Danuta Krotoski, USA; Judy Levin, USA; Gerard Loeber, ISNS; Joanne Mei, USA; Sorrel Namaste, USA; Mohamed Rashed, Egypt; Stéphane Roy, France; Michele Lloyd-Puryear, USA; Ahmad Teebi, Qatar; Bradford Therrell, USA; Peter Van Dyck, USA.

The members of the conference planning working group are as follows: Sana Al Hait, Jordan; Zuhair Al-Hassnan, Saudi Arabia; Jean-Louis Dhondt, France; Ibrahim El Nekhely, Egypt; Hani Atrash, USA; Randa Kamal Raouf, Egypt; Gerard Loeber, ISNS; Sorrel Namaste, USA; Mohamed Rashed, Egypt; Bradford Therrell, USA.

The members of the congenital hypothyroidism working group are as follows: Zuhair Al-Hassnan, Saudi Arabia; Ali Bensalah, Morocco; Habiba Chaabouni, Tunisia; Jean-Louis Dhondt, France; Gilian Engelson, USA; James Hanson, USA; R. Rodney Howell, USA; Randa Kamal Raouf, Egypt; Danuta Krotoski, USA; Sorrel Namaste, USA; Carmencita Padilla, The 
Philippines; Ben-Omran Tawfeg, Qatar; Ahmad Teebi, Qatar; Bradford Therrell, USA.

The members of the survey working group are as follows Jean Louis Dhondt, France; Ibrahim El Nekhely, Egypt; Randa Kamal Raouf, Egypt; Gerard Loeber, ISNS; Sorrel Namaste, USA; Mohamed Rashed, Egypt.

\section{REFERENCES}

1. Loeber JG. Newborn screening in Europe: the situation in 2004. J Inherit Metabol Dis 2007;30:430-438.

2. Bodamer OA, Hoffman GF, Linde M. Expanded newborn screening in Europe. J Inherit Metab Dis 2007;30:439-444.

3. Borrajo GJC. Newborn screening in Latin America at the beginning of the 21st century. J Inherit Metab Dis 2007;30:466-481.

4. Therrell BL, Adams J. Newborn screening in North America. J Inherit Metab Dis 2007;30:447-465.

5. Watson MD, Mann MY, Lloyd-Puryear MA, Rinaldo P, Howell, RR. Newborn screening: toward a uniform screening panel and system. 2006; 8(suppl 1):1S-252S.

6. Newborn Screening Saves Lives Act, 2008. Available at: http://www. govtrack.us/congress/bill.xpd? bill=s110-1858. Accessed December 10, 2008

7. Health Council of the Netherlands. Publication no. 2005/11: Neonatal
Screening. The Hague: Health Council of the Netherlands, 2005. Available at: http://www.gr.nl/samenvatting.php?ID $=1258 \&$ highlight $=$ neonatal $\%$ 20screening. Accessed December 10, 2008.

8. State of the world's children 2008. New York: United Nations Children's Fund (UNICEF), 2008

9. Christianson A, Howson CP, Model B. Global report on birth defects. White Plains, NY: March of Dimes Birth Defects Foundations, 2006.

10. Bittles AH. When cousins marry: a review of consanguinity in the Middle East. Perspect Hum Biol 1995;1:71-83.

11. Bittles AH. A community genetics perspective on consanguineous marriage. Community Genet 2008;11:324-330.

12. Hamamy H, Bittles AH. Genetic clinics in Arab communities: meeting individual, family and community needs. Public Health Genomics 2008; $12: 30-40$

13. Teebi AS, El Shanti LI. Consanguinity: implications for practice, research, and policy. Lancet 2006;367:970-971.

14. Saadallah A, Rashed M. Newborn screening: experiences in the Middle East and North Africa. J Inherit Metab Dis 2007;30:482-489.

15. Middle East and North Africa Newborn Screening home page, 2008. Available at: http://www.nichd.nih.gov/about/meetings/2008/mena2.cfm. Accessed December 10, 2008

16. Therrell BL, David Padilla C. Screening of newborns for congenital hypothyroidism: guidance for developing programs. Vienna, Austria: International Atomic Energy Agency Publications, 2006. 